\title{
New Editor-in-chief for Entomologica Fennica
}

It has been four years since Dr. Niklas Wahlberg began acting as the Editor-in-chief of Entomologica Fennica. Since then, the journal has been recognized as one of the World's leading taxonomic journals, with ecological spice. Sadly, then, in the end of 2004 Dr. Wahlberg decided to withdraw from the editorial duties and focus on his passion, butterfly systematics research. The Editorial Board of Entomologica Fennica wishes to thank Dr. Wahlberg for his remarkable effort in editing and developing the journal.

To find someone to fill such big boots is not always an easy task. Our journal, however, was lucky: the new Editor-in-chief Dr. Kai Ruohomäki (the University of Turku, Finland) was soon found. Dr. Ruohomäki has spent all of his academic career there. He finished his doctoral dissertation in 1990 on the population ecology of the Autumnal moth Epirrita autumnata. (Hence the cover species for volume 16.) Dr. Ruohomäki has continued studying E. autumnata mainly in northern Fennoscandia, where regular outbreaks occur. He has carried out numerous field experiments focusing on herbivory and host-parasitoid interactions. However, Dr. Ruohomäki is not solely an academic entomologist; he began his career as a school boy collecting butterflies and moths, which still remains his main hobby.

Dr. Ruohomäki sees the editorial duties as a great challenge, but is confident. He feels the editorial policy started by Dr. Wahlberg is an excellent basis for continuing to develop Entomologica Fennica. As an ecologist Dr. Ruohomäki feels the journal should increase the percent of ecological publications, especially experimental ones. Although Entomologica is a journal "on all aspects of insects and other terrestrial arthropods", ecology currently represents a minority of published papers. Dr. Ruohomäki would like to begin publishing brief notes, and opinion-type communication papers without new data. In short notes, authors would not necessarily have to follow the limiting "Intro-Mat \& Met - Res - Disc" structure of research papers. However, the policy

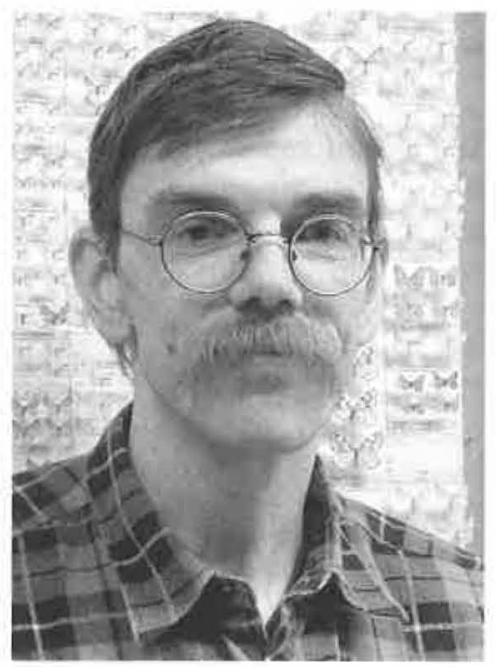

would still not allow faunistic reports of single species or pure species lists, unless they remarkably add to the general faunistic understanding.

The Editor-in-chief shapes the journal based on his/her own background, with influence from editors and the Editorial Board. The demands to maintain high quality, with an increasing number of submitted papers, increase the work load of the editors. Therefore, three associate editors $-\mathrm{Dr}$. Jyrki Muona and Dr. Pekka Vilkamaa, from the Finnish Museum of Natural History, and Dr. Ilari Sääksjärvi, from the University of Turku - were named last autumn. Due to this change, the working conditions for the editors have improved remarkably. Also, the quality of submitted and published papers is probably better than ever, and the economic situation of the journal remains safe. Many if not all of these favourable aspects owe to the work of previous editors and the Editorial Board. The most recent link in this chain, Dr. Ruohomäki will certainly succeed as Editorin-chief, and lead Entomologica Fennica in responding to the challenges of the future.

Matti Koivula

Editor, Entomologica Fennica 